\title{
El álbum fotográfico de Luciano Gallardo: familia y cohesión social
}

\section{The Photo Album of Luciano Gallardo: Family and Social Cohesion}

\author{
Silvana Berenice Valencia Pulido \\ (D) 0000-0003-1424-4199 \\ Fototeca Nacional-Instituto Nacional de Antropología e Historia, México \\ berenice_valencia@inah.gob.mx
}

Resumen: Luciano Gallardo fue propietario de fábricas decimonónicas de "vino mezcal" ubicadas en Jalisco y que corresponden al antecedente de la actual empresa "Tequila Cuervo". La posición social y económica de la familia Gallardo le concedió un gran reconocimiento dentro de la clase burguesa jalisciense de la época, misma que le generó una amplia gama de vínculos laborales y amistosos. Generalmente, los documentos escritos hacen referencia a las relaciones laborales y del ámbito público que poseían personajes como este. Sin embargo, aparentemente existe poca información acerca de la vida privada de la burguesía mexicana. El álbum fotográfico para tarjetas de visita de Luciano Gallardo es testimonio de la vida cotidiana de una familia burguesa de Guadalajara durante la segunda mitad del siglo xix, así como de la cohesión grupal al interior de dicha clase social.

Palabras clave: fotografía; álbum; familia; cohesión social; siglo xIx.

Abstract: Luciano Gallardo was the owner of 19th-century "mescal wine" factories located in Jalisco, corresponding to the history of the company known today as Cuervo tequila. The social and economic position of the Gallardo family won him great recognition within the bourgeois Jalisco class of the time, as well as providing him with a broad range of work and friendship links. Written documents usually refer to labor relations and the public sphere that had characters like this. However, there is apparently very little information 
about the private life of the Mexican bourgeoisie. The photo album for Luciano Gallardo's business cards serves as a testimony of the everyday life of a bourgeois family in Guadalajara during the second half of the 19th century, as well as group cohesion within this social class.

Key words: photography; album; family; social cohesion; 19th century.

Fecha de recepción: 8 de agosto de 2017 Fecha de aprobación: 12 de diciembre de 2017

\section{INTRODUCCIÓN}

S parte de que el álbum fotográfico para tarjetas de visita de Luciano Gallardo es testimonio de la vida cotidiana de una familia burguesa de Guadalajara durante la segunda mitad del siglo xix, así como de la cohesión grupal al interior de dicha clase social.

Esta propuesta se fundamenta en que los álbumes para tarjetas de visita son conjuntos de fotografías, principalmente retratos de familiares y amigos, que fueron recopilados por una determinada familia a lo largo de un lapso extenso de entre 20 y 30 años (Valencia, 2012a, p. 77). En este álbum fotográfico se observa la convivencia de la familia extendida bajo un mismo techo a cargo de Luciano Gallardo como responsable de la misma. Las colecciones de tarjetas de visita evidencian las relaciones sociales y afectivas de la familia propietaria; asimismo, los retratos en tarjeta de visita muestran los elementos de identidad colectiva e individual del grupo social donde estos fueron creados y obsequiados (Valencia, 2012b, pos. 1485-1495). La posición social y económica de este personaje del siglo XIX le concedió un gran reconocimiento dentro de la clase burguesa de la época, misma que le generó una amplia gama de vínculos laborales, amistosos y familiares que se ven reflejadas en las fotografías encontradas dentro de su álbum.

Este trabajo tiene como objetivo esclarecer la forma en que el conjunto de tarjetas de visita contenido en un álbum describe la manera de ser y de representarse de la clase burguesa de Guadalajara en el siglo XIX. ${ }^{1}$ Es posible identificar dichas evidencias al analizar los retratos en tarjetas de visita con-

\footnotetext{
${ }^{1}$ El carácter descriptivo de los álbumes para tarjetas de visita en México ha sido discutido por Valencia, 2012a, trabajo que antecede la presente investigación.
} 
tenidos dentro del álbum de la familia Gallardo como figuras, es decir, al establecer el significado de determinados objetos en relación con otros del mismo campo y horizonte (Bozal, 1987, pp. 20-23). Además, esta investigación ha considerado el análisis de los retratos en tarjetas de su espacio discursivo, considerado como el entorno dentro del cual circularon y para el cual fueron hechas dichas fotografías (Krauss, 1985, pp. 145-163).

Este estudio se afianza en la teoría del conocimiento que Berger y Luckmann (2008) aplican al estudio de la vida cotidiana, al explicar el modo en que los seres humanos consiguen objetivar determinados conocimientos al incorporarlos a su vida diaria, lo que equivale a otorgarle a dichas experiencias un contenido simbólico y significativo; las cuales determinan conductas inconscientes de la vida diaria. Los principales conceptos tratados en el presente trabajo son: la noción de familia planteada por Burke (2000) como una "institución formada por un conjunto de papeles mutuamente dependientes y complementarios entre sí" (p. 7), ${ }^{2}$ la idea de vida cotidiana propuesta por Berger y Luckmann (2008) como la realidad interpretada por los seres humanos a partir de cierta coherencia de los significados subjetivos compartidos socialmente (p. 24) $\mathrm{y}$ el concepto de identidad formulado por Aguado y Portal (1992) como el proceso de identificaciones históricamente apropiadas que le confieren sentido a un grupo social y le da estructura significativa para asumirse como unidad (p. 47). ${ }^{4}$

${ }^{2}$ La noción de familia es una construcción compleja compuesta no sólo por una unidad residencial, sino también por lazos económicos y legales que conforman una comunidad moral, en el sentido de un grupo con el cual sus miembros se identifican y al cual están emocionalmente unidos. Laslett (1972) propone una clasificación familiar basada en las dimensiones y la composición del grupo de casa, distinguiendo tres grupos de familias: simple, extendida y múltiple.

${ }^{3}$ Es importante enfatizar la complejidad en la conformación de la vida cotidiana, motivada por la articulación de diferentes variables que inciden en distintos niveles y magnitudes. Las actividades aparentemente sencillas del diario acontecer tienen un trasfondo muy elaborado, que tienen su origen en el individuo y en la sociedad. Al mismo tiempo, esta idea permite comprender que estas configuraciones subjetivas y objetivas son dos estados de la misma realidad y de la misma historia colectiva que se deposita o inscribe a la vez en los cuerpos y en las cosas.

${ }^{4}$ Las identificaciones surgen en un ámbito cultural específico, a partir del cual los sujetos reconocen sus semejanzas con los miembros de su grupo, al tiempo que se distinguen de los integrantes de otros grupos (Portal, 2003, p. 47). Así, la identidad social surge de la capacidad de autoidentificación y de la apropiación de las identificaciones ajenas en contextos sociales y culturales específicos e históricamente determinados. Las experiencias concretas 
El presente trabajo se contrapone a las propuestas que consideran los retratos de tarjetas de visita como una simulación por aparentar bienestar económico y moral (Massé, 1998, p. 17). Asimismo, se opone a la idea de calificar al retrato fotográfico del siglo xix como arquetípico y reiterativo (Negrete, 2006, p. 84). Finalmente, es preciso aclarar que esta investigación no ha considerado el estudio de los aspectos técnicos de la elaboración de las tarjetas de visitas.

\section{EL ÁLBUM PARA TARJETAS DE VISITA COMO UNIDAD DE ANÁLISIS}

En el siglo XIX, los álbumes para tarjetas de visitas tuvieron un gran auge entre la clase burguesa de la época. Su estudio integral posibilita la comprensión de las relaciones establecidas entre cada uno de sus elementos que tienen sentido en el contexto decimonónico.

La adquisición de retratos en tarjetas de visita por parte de la clase alta fue uno de los fenómenos más característicos del siglo XIX, este tipo de fotografía tuvo buena aceptación entre la clase alta de México desde 1860 hasta que finaliza el siglo xIx. La práctica de intercambiar este tipo de objetos entre familiares y amigos generó la creación de un elemento especialmente diseñado para su resguardo: el álbum fotográfico para tarjetas de visita. Estos álbumes formaron parte de la vida cotidiana de la burguesía mexicana.

El álbum es un formato reconocido por representar una buena solución para resguardar y contemplar colecciones, debido a que una encuadernación provee de protección a su contenido mientras permite acceder a él. Con el gran desarrollo del proceso fotográfico en el siglo xIx, el formato de libro fue la opción natural para resguardar colecciones fotográficas, el cual tuvo adecuaciones para el montaje específico de fotografías. Así, los fabricantes de álbumes tuvieron que realizar innovaciones para encontrar la manera de solucionar el problema de colocar varias tarjetas gruesas en el álbum y que este permaneciera cerrado; se diseñaron hojas gruesas, conformadas por cartón con compartimentos para alojar las tarjetas y recubiertas en ambas caras

a partir de las cuales se construyen las identidades colectivas, al ser históricamente determinada, pueden variar en el tiempo. 
por papel con ventanas que permitieran, al mismo tiempo, ver y sujetar las fotografías (Horton, 1999, pp. 15-16).

Las propuestas analíticas de Berger (2007) y de Krauss (1985) convergen en los álbumes fotográficos, donde los conjuntos de imágenes no se encuentran aisladas, sino que guardan una relación entre ellas.

En primer lugar, Berger (2007) afirma que la fotografía contiene información precisa del instante capturado, la cual constituye una evidencia irrefutable de la existencia de las personas y objetos fotografiados; sin embargo, esta información no determina la razón por la que la imagen fue hecha ni la categoría de uso a la cual pertenece, es decir, el sentido de su existencia. De acuerdo con este mismo autor, el significado de una fotografía se descubre por medio de conexiones temporales, previas o posteriores al momento retratado, en otras palabras, desarrollando su historia. Por ello, los álbumes para tarjetas de visita son el medio ideal para encontrar la significación de las fotografías debido a que la discontinuidad natural de estas imágenes puede compensarse con la relación establecida dentro del álbum con otras fotos. Esta correlación facilita el vínculo del suceso registrado con su desarrollo histórico. Agregando las dedicatorias que algunas piezas fotográficas contienen, se genera cierto grado de certeza al determinar la razón por la que fue realizada la toma y el uso que tuvo (Berger, 2007, p. 91).

Por su parte, Krauss (1985) propone la comprensión de las imágenes dentro de su espacio discursivo, entendido como el ámbito cultural específico al que pertenece una determinada imagen, asumiendo diferentes expectativas respecto a su uso y transmitiendo un conocimiento en particular (p. 146). Para ello, como primer paso es necesario determinar el espacio discursivo en que circularon las imágenes a estudiar, ya que de este se deriva la información que transmite y los términos aplicables a su interpretación por parte de las personas a quienes se dirigió inicialmente. Los retratos fotográficos en tarjeta de visita del siglo xix en México pertenecen al discurso de las relaciones sociales del grupo dominante económicamente debido a que dichas fotografías fueron resguardadas dentro de los álbumes especialmente diseñados para este propósito (Valencia, 2012a, p. 108). Estas imágenes no podían ser apreciadas por todas las personas que accedieran a la casa que tuviera este tipo de ejemplares, ellas sólo eran contempladas por aquellas personas a las que los propietarios de los álbumes seleccionaban por considerarlas dignas de compartir con ellas la colección de fotografías que tenían, debido seguramente a que compartían las mismas relaciones familiares, amistosas o afecti- 
vas con las personas registradas en las imágenes fotográficas. Así, el espacio de estas representaciones está estructurado a partir de un deseo documental o de registro de la forma de ser y de relacionarse de un grupo social específico, la burguesía, en un contexto determinado, México del siglo xix (véase imagen 1).

Por otro lado, generalmente se piensa que los álbumes fotográficos no han cambiado a lo largo del tiempo y se consideran recopilaciones de tomas de aficionados que dan cuenta de los eventos familiares más relevantes (nacimientos, viajes, acontecimientos religiosos y logros escolares) registrados usualmente por el jefe de familia. Sin embargo, es posible encontrar este tipo de álbumes hasta el siglo $\mathrm{xx}$, cuando la tecnología permitió que la práctica fotográfica no requiriera de conocimientos especializados. ${ }^{5}$ Habitualmente, los álbumes de tarjeta de visita están formados principalmente por retratos fotográficos, que en el siglo xIx únicamente era posible realizar en estudios con la intervención de un fotógrafo profesional. ${ }^{6}$ Además, estos compendios de imágenes fueron conformados por diversos miembros de una misma familia, como se detallará más adelante.

Por la época de producción de retratos fotográficos en formato de tarjeta de visita, estas imágenes comparten algunos de los conceptos utilizados en la pintura, como son las dos cualidades esenciales y aparentemente contradictorias que Panofsky (1981) le atribuye al retrato: la individualidad o singularidad y la totalidad o universalidad (p. 195). En este tipo de representaciones se pretende resaltar, por una parte, las características que identifican al modelo del resto de la gente, y por otra, se intenta destacar lo que la persona retratada tiene en común con el resto de la humanidad. En el caso de las imágenes estudiadas predomina la intención de registrar fielmente las características del retratado, no únicamente físicas sino también morales, estas últimas acentuadas a partir de la actitud, la pose y los elementos asociados a la figura del sujeto fotografiado, características tomadas del retrato pictórico (Negrete, 2006, p. 83); al mismo tiempo que se repiten los patrones de vestimenta al estilo europeo como una forma de equipararse al modelo de modernidad predominante en la época. De esta forma, los retratos de tarje-

\footnotetext{
${ }^{5}$ Es hasta 1900 que se amplió el mercado de productos fotográficos de fácil manejo (Monroy, 1997, pp. 52-53).

${ }^{6}$ Considerado profesional debido a la serie de conocimientos técnicos y químicos especializados que se requerían para ejercer dicha actividad y que no eran compartidos por la generalidad de la población.
} 


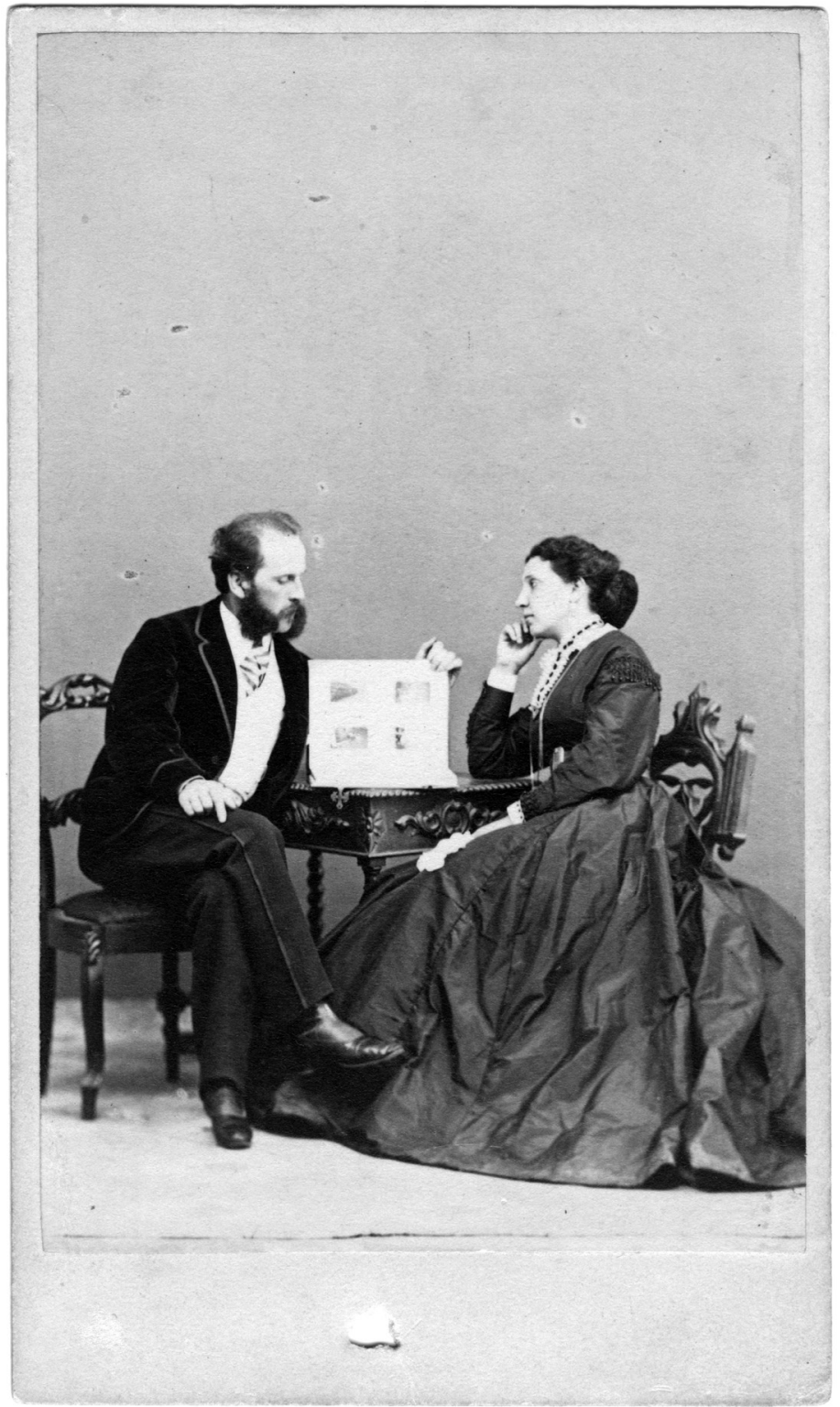

Imagen 1. Representación de la convivencia en torno al álbum fotográfico para tarjetas de visita. (c) 451584 sC.InAH.SINAFO.FN.México. 
ta de visita analizados constituyen imágenes documentales que describen la forma de ser de una clase social.

Aunque estos álbumes son colecciones familiares, es decir, que las fotografías incluidas en ellos fueron recopiladas por distintas personas como parte de una misma familia, estos ejemplares no narran historias o acontecimientos de las personas que lo formaron. Más bien, identifican a las personas con las cuales se relacionan por lazos familiares, amistosos o políticos; describiendo los rasgos distintivos de la esfera social a la que pertenecían y que al mismo tiempo las distinguía de otros sectores.

Finalmente, se plantea el análisis de las tarjetas de visita mediante el concepto de figura, término empleado por Bozal (1987) para referirse a todos aquellos objetos que poseen un significado y que se articulan con otras figuras (p. 21). En esta propuesta, el término de figura hace referencia a un punto de vista en particular, donde se identifica al objeto como parte de un campo determinado, es decir, que corresponde a una forma específica de entenderlo y valorarlo, un modo diferente de mirar ese objeto. Concretamente, las tarjetas de visita no pertenecían al campo de las obras de arte sino a un campo estimativo dentro de las relaciones sociales y familiares de la época. Más claramente, las personas que poseían álbumes de tarjetas de visita en el siglo XIX no apreciaban sus ejemplares sólo por sus atributos estéticos, más bien los tenían en gran estima porque significaban para ellos los vínculos afectivos, sociales y económicos que mantenían con su grupo social.

Figura y significación implican el punto de vista de un sujeto, el cual no es personal ni arbitrario. Dicha perspectiva se adquiere consciente pero también inconscientemente con la percepción cotidiana y sus exigencias, seleccionando las cosas y articulándolas con otras del mismo horizonte ${ }^{7}$ en que se configuran. Sin duda, es posible afirmar que en las tarjetas de visita son tantos los rasgos de la persona registrada, que han desaparecido y solamente ha quedado su figura; en otras palabras, el conjunto de elementos significativos para un sujeto, no los atributos que hacen referencia a ella como sería el caso de los iconos.

${ }^{7}$ Para Bozal (1987), el horizonte son las convenciones comunes a un grupo social, figuras con las que es posible contrastar o relacionar una figura determinada. 


\section{EL ÁLBUM FOTOGRÁFICO DE LUCIANO GALLARDO}

El álbum para tarjetas de visita de la familia Gallardo forma parte del fondo Chapultepec que resguarda la Fototeca Nacional del Instituto Nacional de Antropología e Historia (FN-INAH), donde se identifica con el número patrimonial 10-214901. Este ejemplar contiene un total de 91 fotografías, ${ }^{8} 87$ tarjetas de visita y cuatro tarjetas de gabinete. ${ }^{9}$

Este álbum para tarjetas de visita es de formato vertical (forma francesa). La cartera es de cartón recubierto con piel de color negro, decorada en la tapa frontal con un marco rectangular y en la esquina inferior izquierda tiene un bajo relieve floral que presenta orificios donde se sujetaba una aplicación metálica de la misma forma, también conserva marcas de un broche para cerrar la estructura, las cuales ya se perdieron. El álbum está conformado por 26 folios de cartón recubierto entre dos hojas de papel con cantos dorados. El soporte de cartón presenta una ventana en la que se coloca la tarjeta, mientras que las hojas de papel tienen una ventana de menores dimensiones a la del cartón, la cual sostiene la fotografía y permite que la imagen se pueda ver. Cada folio se encuentra adherido a una escartivana del mismo cartón por medio de tela negra, este mecanismo permite la movilidad de las hojas rígidas para su consulta. En 23 hojas, cada página tiene espacio para albergar dos tarjetas de visita, los otros tres folios presentan una ventana en cada cara para contener una tarjeta de gabinete; pudiendo contener un máximo de 92 tarjetas de visita y seis de gabinete ( 98 fotografías en total). Las ventanas para las tarjetas están enmarcadas por líneas impresas en dorado (véase imagen 2).

La mayoría de las fotografías muestran retratos dedicados principalmente a las familias de Luciano Gallardo y de Jesús Rojas Vértiz y presentan

${ }^{8}$ Los números de inventarios de las tarjetas contenidas en este álbum son los siguientes: 419409, 419416, 419571, 451302, 451609, 451616, 451857-451860, 451901, 451958, 451971, 451992, 451999, 452021-452023, 452025, 452042-452043, 452141-452142, 452157, 452161, 452168, 452202, 452212, 452214, 452220, 452223, 452237, 452405, 452433, 452479, 452532, 453070-453081, 453083-453088, 453090-453109, 453111-453112, 453114-453123, 453692, $453696,453718,465756$ y 838902 . Estos números corresponden al registro de identificación de 2017 de la Fototeca Nacional-Instituto Nacional de Antropología e Historia (en adelante FN-INAH), México, estas mismas tarjetas presentaban anteriormente otros números de inventario. Las imágenes de dichas tarjetas pueden ser consultadas en el catálogo en línea de la FNINAH en www.fototeca.inah.gob.mx.

${ }^{9}$ La medida promedio de las tarjetas de visita es $41 / 2 \times 2 \frac{1 / 2}{2}(10.7 \times 6.3 \mathrm{~cm})$ y de las tarjetas de gabinete es $61 \frac{1}{2} \times 4 \frac{1}{2} "(16 \times 11.5 \mathrm{~cm})$. 


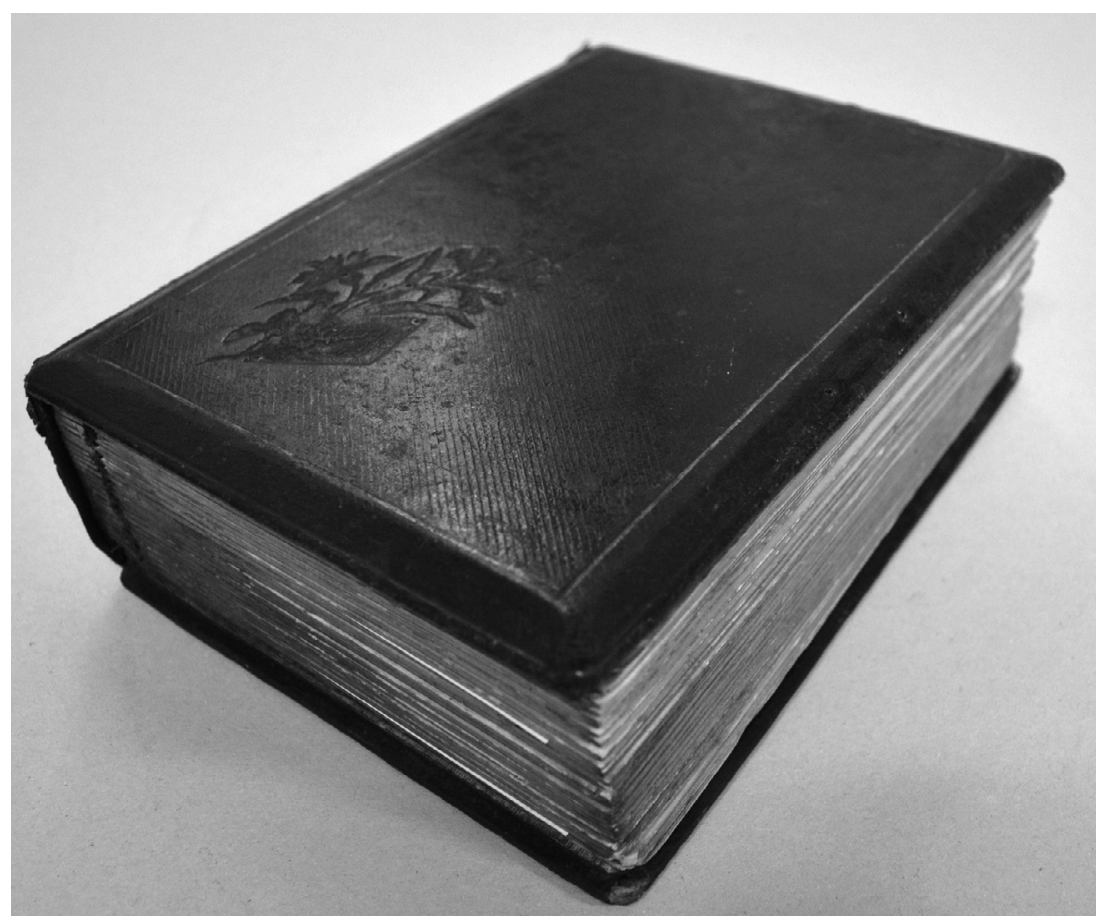

Imagen 2. Vista general del álbum para tarjetas de visita de la familia Gallardo. No. inventario 10-214901. Fototeca Nacional-Instituto Nacional de Antropología e Historia, México.

diferentes fechas entre 1868 y 1901. Gran parte de los datos en las tarjetas hace referencia a Guadalajara, Jalisco, por lo que es posible inferir que el vínculo social de los propietarios del álbum se encontraba en dicha ciudad. Del conjunto de álbumes que resguarda la FN-INAH, este es el único álbum que presenta un equilibrio entre retratos de hombres y mujeres, en la mayoría de ellos existe un predominio de fotografías de varones (Valencia, 2012a, pp. 74 y 98); asimismo, es el álbum que contiene mayor cantidad de imágenes de infantes (Valencia, 2012a, p. 67).

La mayoría de las fotografías se realizaron en tomas de cuerpo completo, encuadre preferido en los inicios del retrato fotográfico (1860 a 1880 aproximadamente), lo cual parece indicar que la mayor parte de las tarjetas incluidas en el álbum fueron recibidas por la familia durante los primeros años en que 
comenzaron a integrar su colección. Aunado al hecho de que los niños eran retratados de cuerpo completo, por lo general para incluir objetos asociados a las actividades infantiles como carriolas y juguetes (Valencia, 2017, pos. 2311). Es posible que con el paso del tiempo, a esta familia le hayan obsequiado menos fotografías, debido a que durante los últimos años del siglo xix predominaron los retratos con acercamientos de la persona registrada (véase imagen 3).

Como se mencionó anteriormente, en este álbum se encuentran mayormente fotografías con dedicatorias al matrimonio formado por Luciano Gallardo y Virginia González Rubio de Gallardo. También destacan las fotografías regaladas a la pareja de Jesús Rojas Vértiz y Josefa Vargas de Rojas Vértiz. No se cuenta con información que permita conocer el parentesco entre ambas familias, sin embargo, es posible inferir una estrecha relación entre ellas debido a que formaron en conjunto un álbum. Las imágenes que reunieron los diferentes miembros de estas familias están fechadas en años similares y la mayoría proceden de Guadalajara, por lo que no es viable pensar que el álbum perteneció primero a una de ellas y después a la otra.

Algunas de las personas emparentadas con estas familias y que regalaron su retrato a alguno de sus miembros son: Inés Peña de González (posiblemente cuñada de Virginia González Rubio), Ma. de los Ángeles Rojas Vértiz de Gutiérrez (familiar de Jesús Rojas Vértiz), Carlos Ma. Rojas Vértiz (sobrino de Jesús Rojas Vértiz y Josefa Vargas), Jesús y Elena Ibarra (sobrinos de Rita Vargas, hermana de Josefa Vargas), Refugio Pacheco y Malagón (sobrina de Luciano Gallardo) y Javier Méndez (sobrino de Josefa Vargas). Como se observa en esta relación, con la información que presenta este álbum no es posible realizar la genealogía completa de las familias que lo conformaron, a diferencia del estudio que sugieren Pariente y Herrera (1993, p. 51); aunque se encontraron imágenes de varios de los integrantes de la familia Gallardo.

Por otro lado, no es viable conocer la fisonomía de todos los integrantes de la familia ya que sólo se encontraron los retratos de algunos de ellos, como los hermanos Gallardo: Filiberto, Luciano, Leocadia y Josefina, y de su papá: Lázaro de Jesús. Así que, al observar el contenido del álbum, estas familias no podrían recordar totalmente ni identificarse con sus ancestros como lo sugieren investigaciones sobre ejemplares del siglo $\mathrm{xx}$, al considerar los álbumes como una galería de antepasados (Mass cit. pos. Negrete, 2006, p. 90), ya que sólo hallarían en él a unos pocos familiares.

En resumen, es posible observar que el álbum para tarjetas de visita de la familia Gallardo presenta características diferentes a las atribuidas a los 

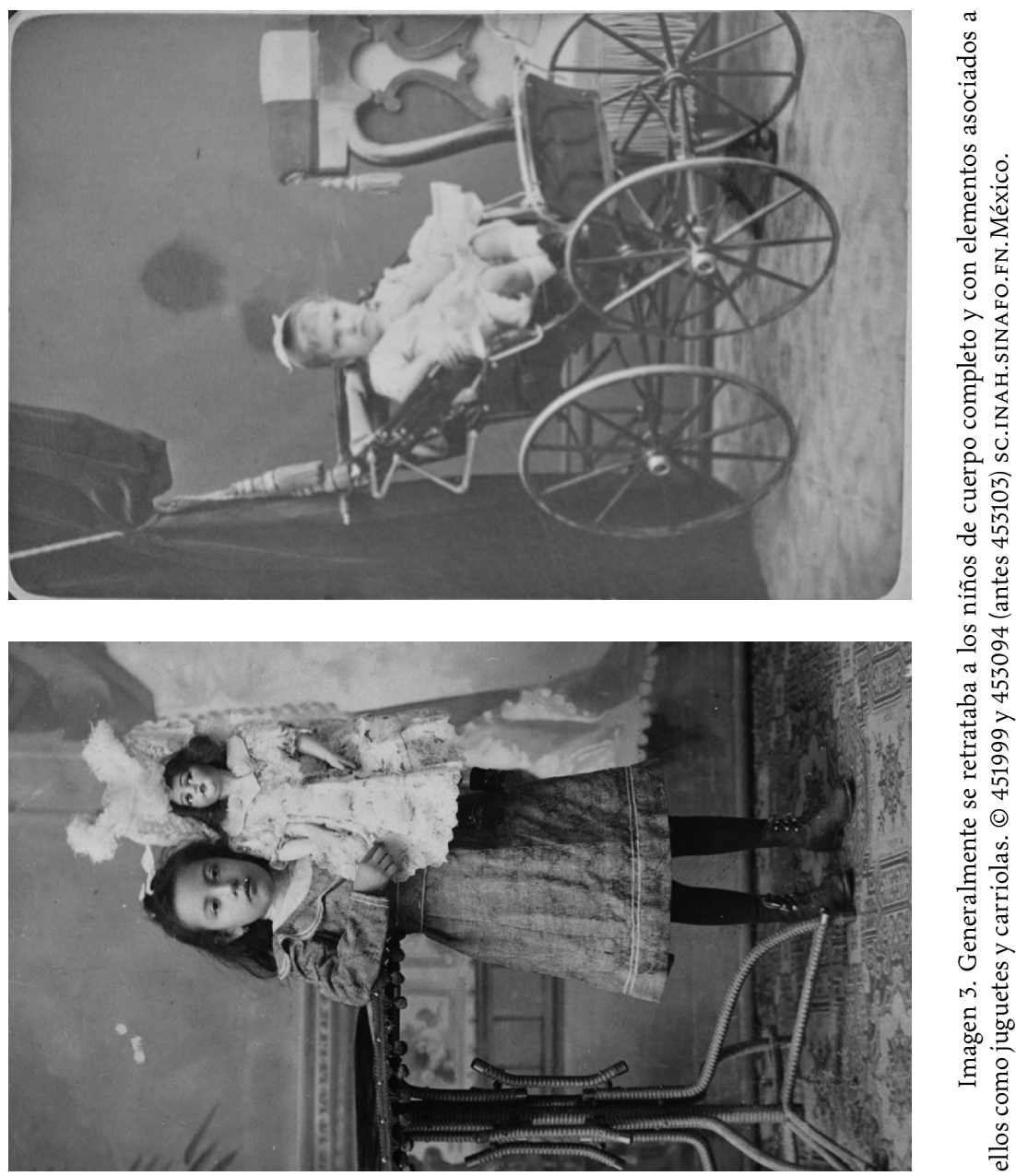
álbumes fotográficos del siglo xx. Este no rememora eventos en particular, ya que no contienen fotografías instantáneas sino de estudio, debido a que en la época de este tipo de imágenes no se contaba con la tecnología para que las personas sin estudios en la materia pudieran realizar tomas fotográficas, ni revelar e imprimir las mismas. Tampoco contiene exclusivamente los retratos de familiares, sino en su mayor parte presenta las fotografías de amistades o conocidos, quienes obsequiaban las tarjetas de visita como un testimonio de amistad, cariño, gratitud o respeto. Finalmente, no se encontraron varias fotografías de una misma persona que muestre sus cambios físicos a través del tiempo, ya que la intención primordial de realizarse un retrato de tarjeta de visita era el de obsequiarlo.

\section{LUCIANO GALLARDO Y FAMILIA}

La siguiente descripción de la estructura de la familia Gallardo y de su actividad dentro de la producción y elaboración de "vino mezcal" en el estado de Jalisco se ha realizado a partir de la consulta de archivos parroquiales, donde se registran los bautizos y matrimonio religiosos, y de archivos municipales, los cuales conservan algunas actas de nacimiento, de defunción y de compraventa de propiedades. Asimismo, considera la revisión de algunos trabajos sobre el desarrollo de la industria tequilera.

Luciano de Jesús Gallardo García-Diego nació en Tequila, Jalisco. Fue hijo de Lázaro de Jesús Gallardo Arrieta ${ }^{10}$ y Leocadia Guadalupe García-Diego Enríquez del Castillo. ${ }^{11}$ La pareja Gallardo García-Diego comenzó su vida familiar en León, Guanajuato; posteriormente se cambiaron a Guadalajara, Jalisco. Fueron propietarios de las destilerías y haciendas que sirvieron como base de la actual casa Tequila Cuervo (Jiménez, 2010, p. 15). Este matrimonio tuvo en total ocho hijos: Aurelio, Filiberto, Benjamín, Indalecio, Carolina, Leocadia, Luciano y Josefina (Jiménez, 2010, p. 28).

${ }^{10}$ Originario de Irapuato, hijo de Luciano Nepomuceno Gallardo Gutiérrez y Juana Arrieta Cardona. Falleció en la ciudad de México el 23 de marzo de 1883 (El Litigante, 31 de mayo de 1885 , p. 4).

${ }^{11}$ Nacida en Guadalajara en 1811, sus padres fueron Salvador García-Diego Moreno y María Francisca Enríquez del Castillo Madrid de la Peña, falleció en la ciudad de México en 1886 y fue sepultada en el panteón francés. 
Se sabe que Aurelio Luis Gallardo García-Diego nació en León el 3 de noviembre de 1831 y se casó en Guadalajara el 19 de octubre de 1857 con Mercedes Abad y Campos, quien murió en 1862. A la postre, vivió en San Francisco, California, EUA donde fundó el periódico Republicano en el año de 1867. Además escribió obras de teatro y poesía, ${ }^{12}$ murió en 1871.

Filiberto Vicente Gallardo García-Diego nació en Guadalajara en 1833. Fue juez de letras en Teocaltiche, Jalisco en la década de $1870 \mathrm{y}$, posteriormente, juez primero de Lagos de Moreno (www.bpe.udg.mx).

Sobre Leocadia Alexandrina, se sabe que también nació en Guadalajara en 1840. Fue reina principal en la corrida de toros de aficionados celebrada el 26 de mayo de 1859 (Cambre, 1904, p. 264).

Por su parte, Josefina Victoria Gallardo García-Diego nació en Guadalajara en 1854. Se casó con Agustín Tornel y Rincón Gallardo ${ }^{13}$ en noviembre de 1873 en Guadalajara, ${ }^{14}$ con quien tuvo una hija: Josefina Tornel Gallardo. Durante 1888 participó escribiendo en la revista El Correo de las Señoras. ${ }^{15}$

Por su parte, Luciano Gallardo García-Diego nació el 19 de febrero de 1844 y contrajo matrimonio con Virginia González-Rubio Torre ${ }^{16}$ en Guadalajara el 4 de mayo de 1882 con quien tuvo dos hijas: Virginia y Guadalupe. Fue propietario de las fábricas de "vino mezcal" La Gallardeña y Los Camichines en Tequila, Jalisco, heredadas de su padre, y de las haciendas San Antonio del Potrero, de las Ánimas, el Ahuilote y el Tecomil (Jiménez, 2010, p. 28). Además, fue presidente de los municipios jaliscienses de Tequila entre 1894 y 1896 y de Tlaquepaque de 1896 a 1897.

La familia de su esposa también estaba relacionada con la producción de tequila en Jalisco, su cuñada Ana González-Rubio Torre se casó con José Flores, quien era dueño de la fábrica La Rojeña, también conocida como La

${ }^{12}$ Algunas de sus obras teatrales que fueron presentadas en diferentes ciudades de México son: El Pintor de Florencia y los Mártires de Tacubaya. Perteneció a varias academias y sociedades de más celebridad en México y en el Estado de Jalisco fue el poeta más popular al publicar tres libros: Sueños y Sombras en 1856; Nubes y Estrellas en 1865, y Leyendas y Romances en 1868 (Villaseñor, 1987, p. 68).

${ }^{13}$ Agustín Tornel y Rincón Gallardo fue hijo de José Tornel y Díez Bonilla y Guadalupe Rincón Gallardo y Villamil, hija del segundo marqués de Guadalupe y Gallardo y vizconde de casa Gallardo (Ortega y Pérez Gallardo, 1902, pp. 116-118).

${ }^{14}$ El Siglo Diez y Nueve, 18 de diciembre de 1873, p. 2.

${ }^{15}$ Primera revista literaria destinada al público femenino que logró durar una década, de 1883 a 1893, fundada y dirigida por José Adrián N. Rico.

${ }^{16}$ Nació en 1855 en Guadalajara, hija de José María González-Rubio Cornejo e Hilaria Torre González. 
Constancia. Después de enviudar, Ana González-Rubio se casa con José Cuervo Labastida quién se dedica también a la producción de vino mezcal y da nombre a la actual empresa Tequila Cuervo. Ana González-Rubio no tuvo hijos en ninguno de sus dos matrimonios, por lo que al morir hereda sus propiedades a su sobrina Virginia Gallardo González-Rubio, quien estaba casada con Juan Beckmann Wilknes y cuyos descendientes son propietarios de la compañía Casa Cuervo (Jiménez, 2010, p. 15).

Las familias que coleccionaron conjuntamente las fotografías que guardaron en álbumes para tarjetas de visita no estaban integradas de la misma manera que en la actualidad como familia nuclear, es decir: madre, padre e hijos; sino como familia extendida: padres, hermanos, hijos, nueras, yernos, etc. Esto se debe en gran parte a la forma en que eran concebidas las atribuciones decimonónicas de los hombres sobre las mujeres.

En el siglo XIX solamente los varones de la burguesía eran considerados ciudadanos y podían ejercer sus derechos políticos, haciendo una distinción en la pertenencia social (Velázquez, 2008, pp. 41-49). Las mujeres no podían tomar decisiones propias, estaban subordinadas a un hombre como cabeza de familia, quien determinaba su proceder de acuerdo con los modelos de comportamiento aceptados socialmente (Parcero, 1992). La sociedad decimonónica calificaba a los hombres como individuos autónomos con voluntad clara y propia, por ello eran considerados como responsables moral y económicamente de la familia en general. En el ámbito privado, como jefes de casa tenían la autoridad para tomar las decisiones sin cuestionamientos por los demás miembros a su cargo.

Esta forma de organización familiar está presente en el álbum fotográfico de Luciano Gallardo. Aunque se puede decir que el ejemplar analizado comenzó a conformarse por la familia que Lázaro Gallardo encabezaba, se ha considerado a su hijo Luciano Gallardo como el propietario del mismo debido a que es él quien continuó al frente de dicha familia a la muerte de su padre.

La fotografía más antigua asociada a esta familia corresponde al retrato de Leocadia, fechado en 1864 y ubicado en Guanajuato. ${ }^{17}$ Aunque no se tiene datos precisos sobre ella, es posible inferir que por alguna circunstancia se fue a vivir a Guanajuato, donde la familia tenía parientes y lazos sociales.

${ }^{17}$ No. Inventario 451901. FN-INAH, México. Inscripción al reverso: "Leocadia Gallardo. Gnato Julio de 64". 
Es probable que por la distancia con sus padres y hermanos, Leocadia les haya obsequiado su imagen.

Posteriormente, se encuentra el retrato que Lázaro Gallardo regaló a su sobrina Refugio Natera y García-Diego en $1866 .{ }^{18}$ Es posible que Refugio Natera pasara alguna temporada con sus tíos, por lo que en este álbum se conserva dicha tarjeta de visita. Es importante destacar que esta fotografía fue dedicada en San Luis Potosí, se sabe que Lázaro Gallado tenía intereses económicos en diversas partes de la república por lo que se desplazaba constantemente, por eso es viable que en uno de sus múltiples viajes haya enviado dicho retrato.

También está el retrato que el señor Collado le obsequia a Josefina Gallardo en $1868 .{ }^{19}$ Así como la fotografía que Filiberto Gallardo dedica a sus hermanas Carolina, Leocadia y Josefina en 1872, firmada en Teocaltiche. ${ }^{20}$ Estas dos tarjetas de visita confirman algunos datos expuestos previamente (véase imagen 4).

En primer lugar, está el hecho de que Filiberto se encontraba distanciado de su familia por cuestiones laborales, como se mencionó previamente, debido a su trabajo en Teocaltiche, población ubicada a $170 \mathrm{~km}$ al norte de Guadalajara rumbo hacia Aguascalientes. En segundo término, las fechas en que se encuentran imágenes dedicadas a Josefina coinciden con los años previos a su matrimonio en 1873, por lo que todavía dichas fotografías se encuentran incluidas en el álbum estudiado. Esta misma situación concuerda con la presencia de un grupo de tres fotografías que resguarda la FN-INAH dentro de otro de sus fondos, las cuales están fechadas en años posteriores al matrimonio de Josefina Gallardo con Agustín Tornel, ${ }^{21}$ por lo cual no forman parte de la colección fotográfica de la familia Gallardo.

De años posteriores se localizaron cuatro tarjetas de visitas que fueron obsequiadas a Lázaro y a Luciano Gallardo como recuerdos de amistad por

${ }^{18}$ No. Inventario 465756. FN-INAH, México. Inscripción al reverso: "Un recuerdo afectuoso a la simpática y mi querida ahijada y sobrina Refugio Natera y García Diego. S. Luis Potosí Julio 28 de 1866. Lázaro J. Gallardo”.

${ }_{19}$ No. Inventario 453093. FN-INAH, México. Inscripción al reverso: "Recuerdo de amistad a la más preciosa tapatía y mi amiga Josefina Gallardo. Dic 141868 P. Collado”.

${ }^{20}$ No. Inventario 451302. FN-INAH, México. Inscripción al reverso: "A mis queridas hermanas Carolina, Leocadia y Josefina, les consagra este recuerdo, en prueba del constante afecto que les profesa Filiberto A. Gallardo. Tescaltiche Nobre $1^{\circ}$ de 1872 ".

${ }^{21}$ No. Inventario 419388, 419389 y 419390 procedentes del fondo Culhuacán. FN-INAH, México. 

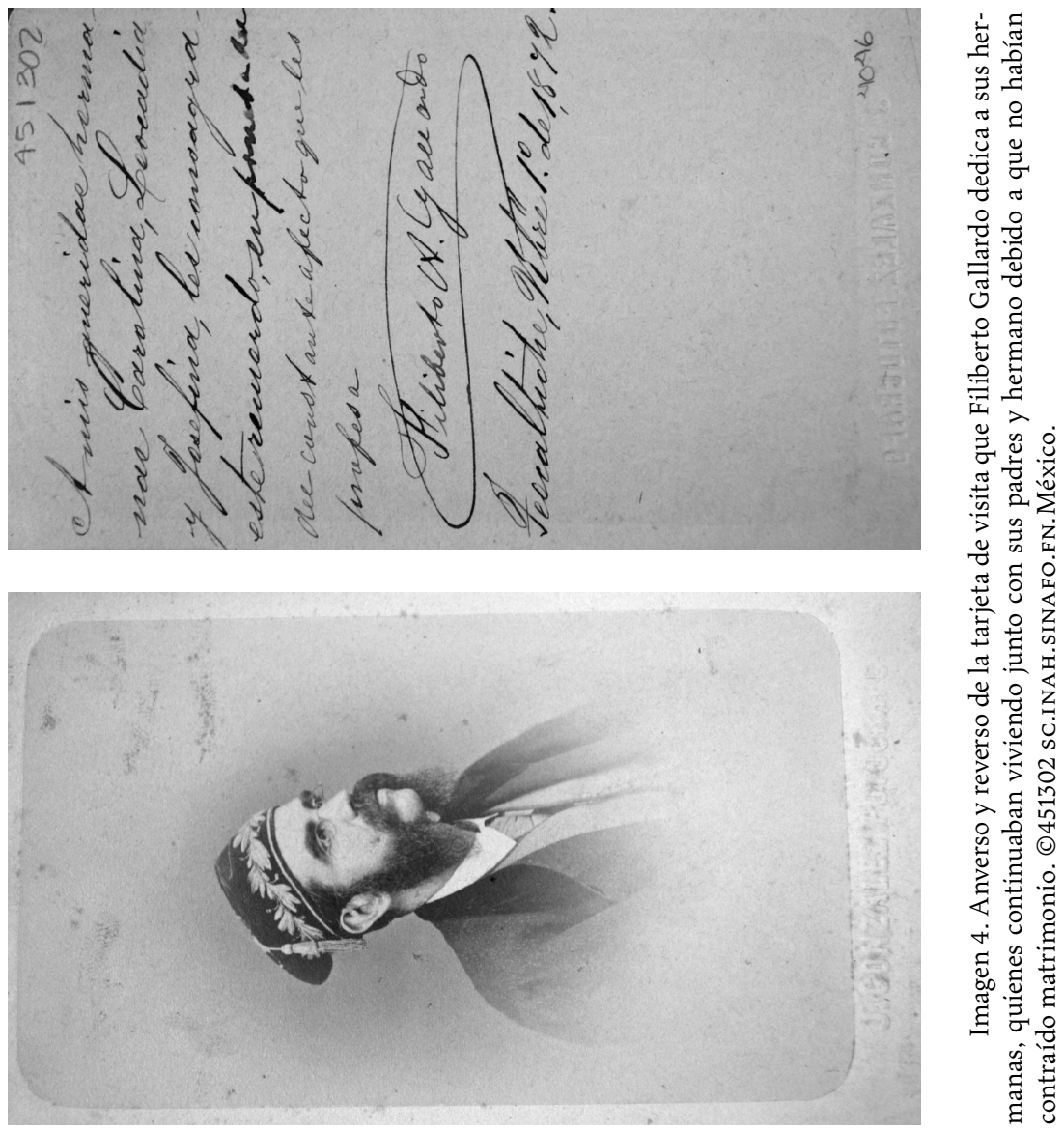
diferentes personas. ${ }^{22}$ Además, se halló el retrato que Inés Peña de González ofreció a Luciano Gallardo y a su esposa Virginia González Rubio en 1883. ${ }^{23}$ Esta fotografía se obsequia en fecha posterior al matrimonio de dicha pareja que se había realizado el año anterior. Asimismo, evidencia que Luciano Gallardo continuó viviendo al lado de sus padres después de haberse casado, a diferencia de sus otros hermanos quienes residieron por separado a partir de su matrimonio.

Finalmente, es necesario mencionar que dentro de este álbum fotográfico se resguardan otras tarjetas relacionadas directamente con la familia Gallardo pero que no presenta datación, como un retrato de Josefina Gallar$\mathrm{do}^{24} \mathrm{y}$ otro de Luciano Gallardo obsequiado a su hermana Josefina; ${ }^{25}$ mismos que deben corresponder a fechas anteriores al matrimonio de Josefina al estar incluidos dentro del presente ejemplar. Igualmente, se encuentra el retrato que Refugio Pacheco y Malagón regaló a su tío Luciano. ${ }^{26}$

A partir de estas imágenes y sus dedicatorias es posible observar algunas de las características de las familias decimonónicas, como la permanencia de las mujeres bajo el cuidado del jefe de familia hasta su matrimonio, cuando pasaban a ser responsabilidad de su esposo. Asimismo, se aprecia la superioridad de las relaciones masculinas hacia el exterior de la familia por medio del predominio de las tarjetas otorgadas a los jefes de esta familia, Lázaro y Luciano Gallardo, sobre la cantidad de fotografías obsequiadas a los demás integrantes de la misma.

\section{IDENTIDAD SOCIAL DE LA FAMILIA GALLARDO}

En la conformación de la identidad social de un grupo existen elementos que comparten las personas que los hacen formar parte de una colectividad, al mismo tiempo dichas características los diferencian de otros grupos. Igual-

22 No. Inventario 452479, 453075, 453076 y 453114 . FN-INAH, México.

23 No. Inventario 451857. FN-INAH, México. Inscripción al reverso: "Sres. Luciano Gallardo y Virginia Gonz ${ }^{z}$ Rubio de Gallardo; Reciban Udes. este como una prueba del acendrado cariño que les profesa Inés Peña de Gonz ${ }^{z}$ Guad $^{a}$ Marzo de 1883".

24 No. Inventario 452168. FN-INAH, México, inscripción al reverso: "Josefina Gallardo".

25 No. Inventario 453718. FN-INAH, México. Inscripción al reverso: "A mi muy bella y muy odiada hermana Josefina en prueba de mi amor fraternal. Luciano".

${ }^{26}$ No. Inventario 453104 FN-INAH, México. Inscripción al reverso: "A mi querido tío Luciano como un recuerdo le da ..., su sobrina. Refugio Pacheco y Malagón”. 
mente, al interior de una clase social identificada como conjunto homogéneo, se presentan patrones de comportamiento diferenciados que conforman divisiones internas, es decir, un colectivo unificado puede estar formado por grupos más pequeños con ciertas diferencias y al mismo tiempo similitudes.

El intercambio y el coleccionismo de retratos en tarjetas de visita permite esclarecer elementos individuales y colectivos de comportamientos cotidianos de la clase burguesa decimonónica en México, como se ha visto en estudios comparativos entre los álbumes de tarjetas de visita que resguarda la FN-INAH (Valencia, 2012a). Las personas que crecieron dentro de este grupo social aprendieron y adoptaron desde la infancia los principios de identidad que los caracteriza como unidad y al mismo tiempo las diferencias de otras colectividades.

En un principio los elementos identitarios de la burguesía mexicana se fueron conformando al mismo tiempo por equiparación de la misma clase en Francia y por contraste con los demás sectores de la población en México (Valencia, 2017, pos. 2155). En consecuencia, es posible entender que la introducción al mercado de las tarjetas de visita, responde a las exigencias que presentaba la clase burguesa por reconocerse y reafirmarse como unidad social dominante. Las tarjetas de visita, interpretadas como capital cultural material y simbólico, aseguran un beneficio de distinción proporcionado por la singularidad necesaria para su apropiación y un beneficio de legitimidad que consiste en el hecho de ser como es necesario ser, por ello son bien acogidas en México.

En este proceso de construcción de la identidad social de un grupo pueden reconocerse las intenciones de pertenencia $y$, al mismo tiempo, de diferenciación (Portal, 2003, p. 47). Las imágenes de tarjeta de visita aluden a la construcción de la identidad personal como parte de una elite -proceso de inclusión- diferenciada de otra población con limitaciones económicas, políticas y educativas que no tiene acceso a la representación fotográfica -fenómeno de exclusión.

La diferenciación de la burguesía en contraste con los indígenas en México durante el siglo xix puede observarse en las fotografías de los "tipos mexicanos". Las fotografías de tipos mexicanos contrastan con las tarjetas de visita de la burguesía mexicana en tres aspectos principales: el prototipo racial, la indumentaria y los elementos decorativos.

Las imágenes de la burguesía se relacionan con la necesidad de este sector de reafirmarse como colectivo que comparte un entorno social de auge 
económico, asociado también a las buenas costumbres y a la honorabilidad, resultando ser un medio de expresión del bienestar social y económico.

En este sentido, los elementos encontrados en las fotografías de la familia Gallardo reafirman la autoidentificación de dicho sector social al formar parte de él. Por ejemplo, esta familia mantiene lazos con la realeza mexicana del imperio de Maximiliano, esta relación se manifiesta en el retrato que Lázaro Gallardo obsequió a nombre de su hijo Luciano a la señorita Luisa Rincón Gallardo en $1870,{ }^{27}$ familiar del marqués de Guadalupe Gallardo; de igual forma, se evidencia en el matrimonio de Josefina con un miembro de esa misma familia. Además, dentro de este álbum se encontró el retrato que Enrique Robles Rocha regaló a su tía en 1882, ubicado en Guanajuato, ${ }^{28}$ quien fue hijo de Luis Robles Pezuela ${ }^{29}$ y sobrino de Manuel Robles Pezuela; ${ }^{30}$ asimismo, hay una fotografía de este último. ${ }^{31}$ No se conoce la relación exacta que existía entre las familias Gallardo y Robles, pero es probable que se haya originado desde el origen de Lázaro Gallardo en Guanajuato.

Por otra parte, en los álbumes de tarjetas de visita es posible distinguir las diferentes características que los integrantes de la clase dominante asumen a partir de sus retratos fotográficos.

La teoría del conocimiento de Berger y Luckmann (2008) aplicada a la vida cotidiana, estima que los seres humanos interpretan la realidad a partir de cierta coherencia en los significados subjetivos compartidos por un grupo. La adopción de patrones de comportamiento unificados supone una adaptación ambiental y social de las personas a partir de un análisis de las expectativas que la sociedad tiene de cada individuo. La habituación al cumplimiento de la forma de ser y comportarse socialmente aceptadas, representa la repetición de determinadas actitudes, las cuales se realizan con

${ }^{27}$ No. Inventario 452141. FN-INAH, México. Inscripción al reverso: "Ausente Luciano, manda su padre un fino recuerdo y por su encargo a la Sta. Luisa Rincón. Lázaro J. Gallardo. Guadalaja julio 9 de $1870 "$.

${ }^{28}$ No. Inventario 453081. FN-INAH, México. Inscripción al reverso: "A mi apreciable tía y amiga Luz Zapiain de Robles como un recuerdo de mi sincero afecto dedico este. Enrique Robles Rocha. Gto. ...3 1882".

${ }^{29}$ Fue ministro de Fomento durante el imperio de Maximiliano, era coronel graduado en ingeniería y también fue reconocido como Gran Oficial de la Orden Imperial de Guadalupe (Almanaque, 1866, p. 83).

${ }^{30}$ Presidente interino del 24 de diciembre de 1858 al 21 de enero de 1859 por parte del partido conservador.

${ }^{31}$ No. Inventario 838902. FN-INAH, México. Inscripción al reverso: "Robles". 
economía de esfuerzos gracias a las disposiciones adquiridas que funcionan como automatismos. Este proceso en el que los seres humanos consiguen objetivar cierto grado de conocimiento, se ve reflejado en la forma en que la familia Gallardo se ve a sí misma como parte de la burguesía mexicana de la segunda mitad del siglo XIx, lo cual se expresa en la manera específica en que se representan en las fotografías estudiadas.

En esta época predominaba la aceptación de una relación "natural" del ámbito público, como la política, la ciudadanía y el poder, con la identidad social masculina; en correlación, prevalecía la asociación inherente de la esfera privada con las mujeres. En el entorno púbico se reafirmaba su supremacía de los varones sobre las mujeres y los niños en todos los aspectos.

Las características atribuidas en la época como inherentes a los varones, se observan en gran parte de las tarjetas de visita analizadas. Comúnmente, la forma de vestir era muy cuidada debido a que representaba la primera impresión de una persona, en el caso de los hombres de la burguesía representa elegancia y pulcritud, a diferencia de las clases trabajadoras. Sin embargo, la indumentaria masculina era más sencilla y cómoda, en comparación con la femenina, debido a las actividades laborales que les correspondían, es decir, en su transitar por la vida pública de la época.

La actitud varonil decimonónica se asocia a la seguridad, ya que de ellos era la capacidad de toma las decisiones adecuadas. En general, en las fotografías estudiadas es posible observar esta particularidad de los hombres, su mirada que se dirige directamente al espectador de forma firme, y en algunas ocasiones retadora a manera de evidenciar su valentía, reforzada por elementos de ilustración y estrategia como libros, tinteros y mapas (Valencia, 2017, pos. 2265).

La masculinidad no sólo se manifiesta en las tarjetas de visita sino en la conformación misma de los álbumes donde se coleccionaban estas imágenes. Lázaro y Luciano Gallardo obtuvieron las tarjetas de visita que reunieron en su álbum gracias a sus relaciones sociales y laborales, es decir, en el ámbito de la vida pública donde se desenvolvían. Cabe destacar que las mujeres de quienes aparecen retratos en este álbum mantenían una relación familiar con los dueños de estos, única posibilidad para no considerar impropio el regalar la propia imagen de mujer "educada y de buenas costumbres".

Se ha mencionado anteriormente que el proceder de las mujeres del siglo XIX estaba orientado por la voluntad de los hombres de su familia. De 
igual forma, la construcción social y cultural de la representación del cuerpo femenino estaba determinada por la concepción que los varones tenían acerca de la mujer, la cual fundamentaban en discursos legales y éticos de lo que debía considerarse como propio e impropio de ellas (Nead, 1992, p. 19). Así, el repertorio patriarcal de estereotipos femeninos se estipulaba en ideal físico y estético de la época, los cuales eran construidos socialmente. La mujer desempeña a la vez el papel del objeto visto y del sujeto que ve, forma y juzga su imagen contrastándola con ideales culturales y ejerce una autorregulación, su identidad está enmarcada por las imágenes que definen la feminidad (Nead, 1992, p. 25), siempre asociada al ámbito privado de la familia, las labores hogareñas y la crianza de los hijos.

Los atributos que la sociedad decimonónica relacionaba con las mujeres, se manifiestan en la forma en que ellas son fotografiadas en las tarjetas de visita.

Como se ha expuesto previamente, la representación del cuerpo femenino tenía la intención de ser admirado por los varones, esta forma de mirar a las mujeres puede identificarse en fotografías donde la postura en que se colocan las modelos permite observar mayor cantidad de sus atributos, prefiriendo una toma de tres cuartos en donde se reconocen rasgos de dos planos: frente y lateral, además el registro de cuerpo completo refuerza esta idea (Valencia, 2017, pos. 2293-2300) De acuerdo con Parcero (1992), la mujer adinerada del siglo xIx era catalogada por su gracia, exquisitez, buena educación, belleza y buen gusto en su vestimenta, lo que hacía más fácil el hecho de conseguir marido (véase imagen 5).

La estructura de las imágenes fotográficas representa la insistencia en la unión familiar, reforzando la relación madre-hijo como idealización de la función de la mamá dentro de la familia, fortaleciendo valores sociales y normas de comportamiento implícitas en la propuesta visual.

En la primera infancia, los niños y niñas suelen representarse asexuados, es decir, sin elementos que distingan su género. Posteriormente, se fotografían de acuerdo con las identidades que deben ir tomando según los parámetros de la sociedad decimonónica (Valencia, 2017, pos. 2326). Así, los niños se retratan con actividades del campo identificadas como masculinas, y las niñas aparecen con flores relacionadas con la feminidad o con muñecas en una clara asociación con su posterior función de madres. 


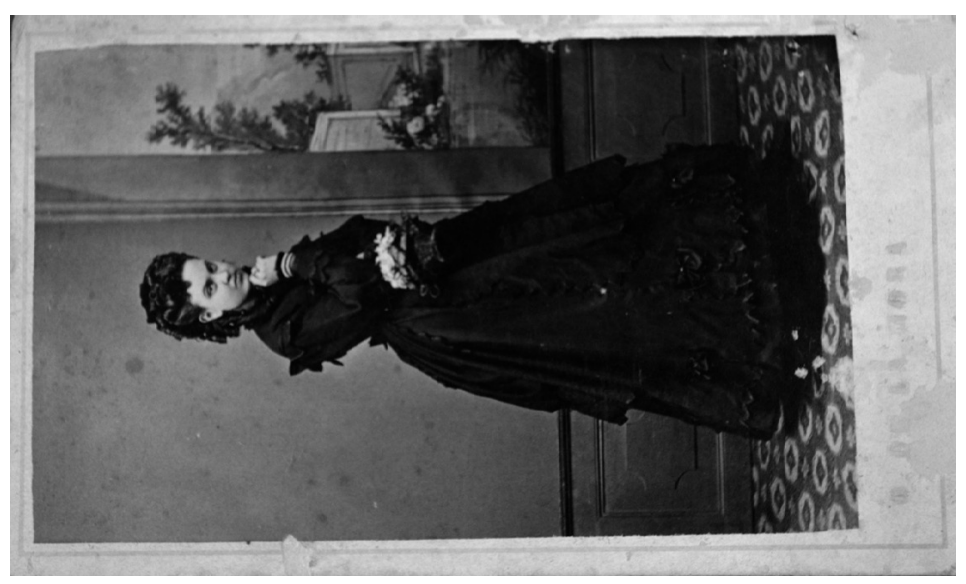

뭉

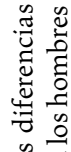

胥

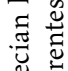

䓀

焉.

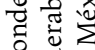

考

윰 ठ0.

党

藏要

氙焉

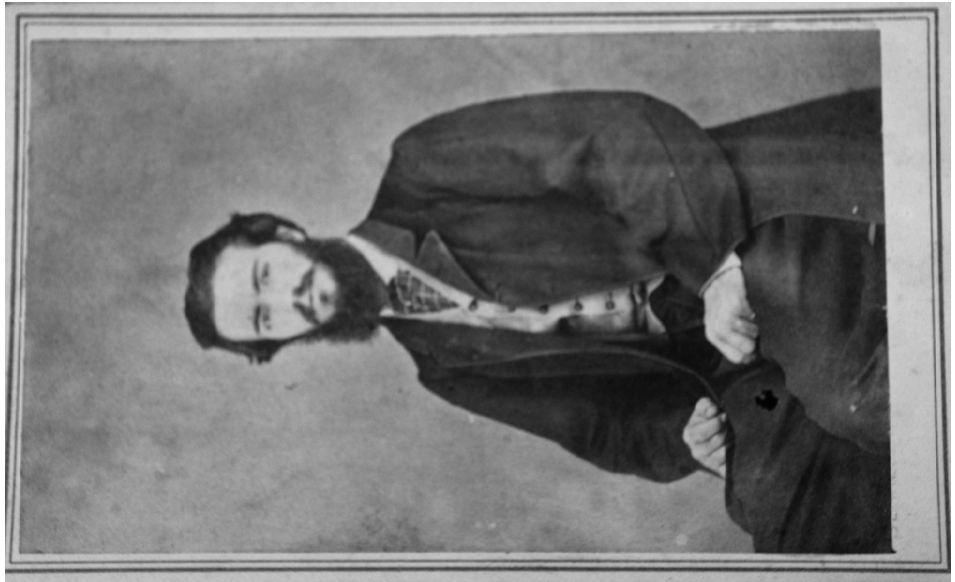

을ํ

ช

入ิ

웜

苛产 令

3 至

응 ำ

足

ت

幽

เ

ปี

政

苞

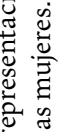




\section{CONCLUSIONES}

El álbum para tarjetas de visita de Luciano Gallardo es testimonio de la vida cotidiana de una familia burguesa de Guadalajara durante la segunda mitad del siglo XIX. La conformación de este ejemplar, muestra la estructura y el significado de las relaciones sociales y familiares de este sector. En él se expresa la forma de ver el mundo de la comunidad a la que pertenecen sus propietarios. Este modelo ideal también se manifiesta en las formas de representación en los retratos de este sector social, evidenciando las ideas de cómo debía ser cada persona perteneciente al grupo económicamente dominante en México.

La asociación de las tarjetas de visita dentro de un álbum les confiere un significado especial para sus poseedores, esta cualidad las conceptualiza en figura. De esta forma, los retratos no sólo rememoran a la persona registrada en ellos, además constituyen un punto de referencia mediante el cual los propietarios de los álbumes pueden contrastarse para adecuar su comportamiento y continuar así formando parte del mismo grupo social. Estas colecciones significan para las familias que las reúnen una forma tangible de pertenencia a una elite identificada con la civilización y el progreso, cualidades deseables en la época.

Concretamente, las tarjetas de visita pertenecían al campo estimativo dentro de las relaciones sociales y familiares de la época. Más claramente, las personas que poseían álbumes de tarjetas de visita en el siglo XIX no apreciaban sus ejemplares sólo por sus atributos estéticos, más bien los tenían en gran aprecio porque significaban para ellos los vínculos afectivos, sociales y económicos que mantenían con su grupo social. La mayoría de las dedicatorias encontradas en este álbum hacen referencia al hecho de regalar la propia imagen contenida en la tarjeta de visita como un recuerdo de amistad con la persona a quien se ofrece. Por ello, la contemplación de los retratos de este álbum permitía a la familia Gallardo equipararse e identificarse con sus amistades, lo cual reafirmaba su pertenencia al círculo social económicamente dominante en México.

Los retratos en tarjetas de visita fueron hechos con la intención de que circularan entre familiares y amistades, por lo que la información que transmiten está dirigida al ámbito de la vida privada. Así el espacio discursivo al que pertenecen estas imágenes es al de las relaciones sociales de la burguesía decimonónica en México, como puede observarse en las fotografías que coleccionó la familia Gallardo en su álbum fotográfico. 
El concepto de vida cotidiana puede aplicarse al estudio de los álbumes de tarjeta de visita que contengan retratos de familiares y amigos de los propietarios, como es el caso del ejemplar analizado, debido a que en ellos se reflejan diferentes aspectos del diario proceder del sector al que pertenecen. Las formas de vestir y de comportarse son actitudes aprendidas y determinadas por el grupo social de origen, las cuales se adoptan y repiten a diario de forma casi inconsciente.

Las fotografías que contiene el álbum de Luciano Gallardo son consistentes con la estructura familiar que mantenían las familias burguesas del siglo xIX en México, donde podían convivir diferentes parientes bajo un mismo techo, conformando una familia extendida. En esta organización familiar, las mujeres solteras siempre estaban bajo la protección de un varón como jefe de familia, como se ha visto en los retratos y las dedicatorias analizados.

El intercambio de tarjetas de visita en el grupo económicamente dominante de Guadalajara en el siglo xIx, y en México en general, se asocia al sistema de reciprocidad, donde el regalo no tenía en sí un valor económico, pero mantenía la solidaridad social, como puede observarse en el conjunto de imágenes que resguarda el álbum de la familia Gallardo. A diferencia de otros objetos de lujo, su uso pertenece exclusivamente al ámbito privado, al ser una forma de exhibición limitada a la familia y amistades con quienes se compartía su contemplación. Este hecho equipara estas colecciones como refuerzo de la autoidentificación del grupo hacia su interior, por las similitudes con sus iguales. De esta forma, en las tarjetas de visita contenidas dentro del álbum de la familia Gallardo es posible encontrar elementos de la identidad colectiva e individual que comparte con el resto de la burguesía decimonónica en México.

\section{LISTA DE REFERENCIAS}

Aguado, C. y Portal, A. M. (1992). Identidad, ideología y ritual. México: UAm Iztapalapa. Almanaque imperial para el año 1866 (1886). México: Imprenta del Gabinete Imperial. Berger, P. y Luckmann, T. (2008). La construcción social de la realidad. Buenos Aires: Amorrortu.

Berger, J. (2007). Apariencias. En J. Berger y J. Mohr, Otra manera de contar. Barcelona: Gustavo Gili. 
Bozal, V. (1987). Mímesis: las imágenes y las cosas. Madrid: Visor Distribuciones-Ediciones Antonio Machado.

Burke, P. (2000). Historia y teoría social. México: Instituto Mora.

Cambre, M. (1904). La guerra de los tres años. Guadalajara: Imprenta y Encuadernación de José Cabrera-López Cotilla y Tesmo.

Horton, R.W. (1999). Historical Photo Albums and Their Structures. En Conservation of scrapbooks and albums (pp. 13-20). USA: AIC-Book and Paper Group and Photographic Materials Group.

Jiménez, M. C. (2010). La cofradía de las benditas ánimas del purgatorio de Tequila. Su participación en la formación del paisaje agavero. Guadalajara: Impre-Jal.

Krauss, R. (1985). La originalidad de la vanguardia y otros mitos modernos. Madrid: Alianza Editorial.

Laslett, P. (1972). Household and Family in Past Time. Cambridge: Universidad de Cambridge.

Massé, P. (1998). Simulacro y elegancia en tarjetas de visita. Fotografías de Cruces y Campa. México: INAH.

Monroy, R. (1997). De luz y plata. México: INAH.

Nead, L. (1992). El desnudo femenino. Arte, obscenidad y sexualidad. Madrid: Editorial Tecnos.

Negrete, C. (2006). Valleto Hermanos: fotógrafos mexicanos de entresiglos. México: IIE-UNAM.

Ortega, R. (1902). Estudios genealógicos. México: Imprenta de Eduardo Dublán.

Panofsky, E. (1981). Los primitivos flamencos. Madrid: Cátedra.

Parcero, M. L. (1992). Condiciones de la mujer. México: INAH.

Pariente, J. L. y Herrera, O. (1993). El álbum familiar del general Pedro José Méndez. México: UAT.

Portal, A. M. (2003). La construcción de la identidad urbana: la experiencia de la pérdida como evidencia social. Alteridades 13(26), 45-55.

Valencia Pulido, S. B. (2012a). Álbumes de tarjetas de visita en la segunda mitad del siglo XIX en México como documento para la historia social (Tesis de doctorado inédita) UAeH, México.

Valencia Pulido, S. B. (2012b). Álbumes de tarjetas de visita en la segunda mitad del siglo xIX en México como documento para la historia social. Boletín Científico Edähi, 1.

Valencia, S. B. (octubre, 2017). Identidad de la burguesía mexicana en las tarjetas de visita. En M. J. González Manrique (coord.), Imagen y culturas. Estudios inter- 
disciplinarios en torno a la imagen (vol. 2) [Kindle Edition]. México: Instituto de Ciencias Sociales y Humanidades-Universidad Autónoma del Estado de Hidalgo. Velázquez, G. (2008). La ciudadanía en las constituciones mexicanas del siglo xIX: inclusión y exclusión político-social. En La democracia mexicana. Acta Universitaria, 18, 41-49.

Villaseñor, R. (1987). Las calles históricas de Guadalajara. Guadalajara: Gobierno de Jalisco.

\section{HEMEROGRAFÍA}

El Litigante. 31 de mayo de 1885.

El Siglo Diez y Nueve. 18 de diciembre de 1873. 